\title{
Model Of Social Responsibility Planning Pt. Biofarma In Jasinga District, Bogor Regency
}

\author{
AgusRahmat $^{1}$, R. Herry ${ }^{2}$ \\ $\{1$ agus.rahmat@unpad.ac.id $\}$ \\ ${ }^{1}$ Universitas Padjadjaran, Indonesia \\ ${ }^{2}$ PT Biofarma (Persero), Indonesia
}

\begin{abstract}
For PT. Biofarma, the benefits of the existence of the company are not only to meet economic objectives or profits and to fulfil of regulation, or just to behave ethically. The commitment held and implemented by PT Biofarma is, the determination to take a series of actions that demonstrate social benefits for the existence of the company in the community outside the company's interests. To achieve its success, the harmony between social responsibility activities with values, culture and the needs that exist in the community around the company becomes a necessity. The first activity conducted by PT. Biofarma in order to achieve harmony in its corporate social responsibility activities is to analyse environmental through a mapping of potential resources, socio demographics, and facilities in the form of public service centres or so-called social mapping. The method used to reveal the social characteristics of the community around the company is a qualitative method with data collection techniques used in the form of structured interviews and focus group discussions (FGD). The results of this social mapping provide an overview of what activities Biofarma should do for the community, who or which group should be targeted by PT. Biofarma and whom (whether individuals or organizations) should be made as partners of Biofarma in the implementation of corporate social responsibility.
\end{abstract}

Keywords: Corporate social responsibility, economic goals, environment, social mapping, harmony,.

\section{Introduction}

PT. Biofarma (Persero), is a State-Owned Enterprise (BUMN) with fully owned shares of government, initially was called (in August 1890) pareVaccinogene or Landskoepokinrichting. Today the company is known as PT. Biofarma, has become a company that concentrates its products on manufacturing vaccines and antisera with internationally recognized quality.

As one of the State-Owned Enterprises (BUMN), the ability to survive and even develop themselves for more than 125 years is evidence of its credibility as a company that has the ability to produce high-quality vaccines and antisera that are highly competitive or at international level. This ability is the result of the support of various elements such as research and development by the company, submission and compliance of the company with existing laws and regulations, and its ability to live in harmony with the environment both at the local level and the wider environment. 
For companies whose products are used in various countries (international level companies), submission to the rules and capabilities in terms of quality of goods and transparent management is apparently not enough, especially to compete in the international level. Developed and developing countries (including countries who are the consumers of Bio Farma products) have agreed that they will only accept or use goods produced by environmentally friendly companies, companies that care about the environment, companies that are working to achieve Millenium Development Goal's (MDG's), even in recent years their requirementsare no longer only at the MDG's level. Companies are also required to participate in dealing with social problems faced by the wider community (Sustainability Development Goals (SDG's)).

Considering at what happens in the international environment, it appears that Friedman's thoughts (Idowu; 2011, Boeger et al; 2008, Aras and David Crowther; 2009) which says that the only task of management is to produce as much goods as possible to obtain maximum profit,in this case seems to have to be reviewed. For now, many goods produced will only be purchased if the company cares and participates in handling social problems faced by the community.

Seeing the ability of Biofarma to penetrate the market in more than 140 countries, it can be concluded that this condition occurs as one of the results of the activities of environmental management supersystem scanning and Biofarma's management commitment towards changes occur in the environment.

Actually the involvement of companies in Indonesia including State-Owned Enterprises (BUMN) is not only done by Biofarma. Other companies especially SOEs also get involved.This is because for companies categorized as SOEs, corporate social responsibility activities, also known as environmental development, are a necessity as stated in the Law.

The interesting thing about Biofarma compared to other companies, especially those included in the SOE category is not only its ability to penetrate or is accepted by various countries in the world which require that the company should be involved in handling social problems, but also shown through the acceptance of various awards including a gold award for corporate social responsibility in Indonesia for four years in a row. So it is not surprising that Biofarma is one of 30 companies that have received World Health Organization (WHO) prequalification from a total of 200 vaccine producing companies in the world. This condition can be interpreted that Biofarma has the ability of environmental supersystem scanning to have the ability handle environmental issues appropriately.

The ability of Bio Farma in implementing CSR is inseparable from the commitment of Biofarma which has established itself to apply the internationally accepted corporate social responsibility (CSR) standard, namely ISO 26000: 2010 Guidance on social responsibility. The consequences of this commitment have consequences for ability of Biofarma to act appropriately in helping social problems not only occur in the company's operating environment so far, but also required in handling social problems in the new social environment which will be entered by Biofarma,especially which is related to the development or relocation of buildings of the production inJasinga sub-district in Bogor Regency.

Based on what Biofarma has done and the awards achieved, it is interesting to find out how Biofarma has developed a corporate social responsibility or its environmental development model of planning. This study was conducted to get answers of this issues. 


\section{Social survey and mapping.}

The first step taken by Biofarma to plan corporate social activities is to conduct social mapping. This activity is carried out based on the awareness of the value of social maps for the company's social activities. At the concept level, the value of this map has also been put forward by several experts such as [1] which basically helps people think more effectively because mapping helps groups to manage complexity

The company environment is such a complex place, at least in terms of types and problems. Therefore, mapping is used by Biofarma as a first step before planning activities. This mapping activity is carried out with more emphasis on qualitative methods of activity. For Biofarma, the application of qualitative study has been used related to its ability to provide information in the community as an in-depth description of speech, writing, and behavior that can be observed from an individual, group, community and certain organizations, although in reality, some of the characteristics of the data are quantitative.Therefore, this method is considered by Biofarmaas being able to give understanding to the company of social reality from the perspective of the subject of study.

The information collected by Biofarma in this study concerns several groups of information, namely: (1) information about the actors; (2) information about the social position and role of the actor; (3) information about the degree of power of the actors, (4) information about the forum and mechanism by which the community can discuss general / public interests; (5) information on the potential for sustainable livelihoods; (6) information about needs; (7) information on types and vulnerable groups; (8) information about social problems.

This series of information is then processed by Biopharma by grouping them based on the type, closeness or similarity of information and the separation of some information that is different in type or other similarities. For some qualitative information, in addition to grouping Biofarma, it also processes information by sorting based on the frequency of occurrence.

The results of this processing provide information to Biofarma about: (1) groups of actors, both individuals and groups with all networks of relationships in the community; (2) The position and social role of actors in people's lives; (3) the degree of strength of each actor in the community, which is shown through the density of relations of the actors; (4) mechanisms and or forums which are used by the community in discussing general/ public interests; (5) the potential for sustainable livelihoods owned and present in the study subject environment. This potential includes human resources, natural resources, social capital, financial capital, and public infrastructure conditions; (6) community needs; (7) types of vulnerability and vulnerable groups; (8) social problems or problems faced by the community.

The results of information processing on the actors, position and role as well as the degree of power of the actors give Biofarma a picture of who is the leader [2] in the target community. Leaders who emerged from the results of this study were formal and informal [3], it depends on the characteristics of the community. In a religious community, the leaders who appear most often come from informal leaders [3], such as religious figures (Adalat Khan;), while in societies with ordinary characteristics, the people who are predominantly more than formal leaders [4] like village leader with all its officials. 
The benefits gained by Biofarma by knowing leaders in the target community isto usethem as personal channel of information [5] for receiving and supporting biopharma social activities in the target community.

The results of the processing on mechanisms and forums in the target region make Biofarma know the organization that can be used byBiofarma as a forum for the target of Biofarma's social activities to exchange experiences about problems faced in daily life or Biofarma to know what organizations exist in local communities [6] who can be used as Biofarma partners in carrying out social activities in the target area [7].

The potential for sustainable life explored by Biofarma relates to aspects of the natural and social environment, both real and latent ones such as skills, education, (Pisano; 2015), income, culture and natural resources and their use so far.

The basis of human activity is to meet the needs of life.For Biofarma, the social program that is carried out is basically to fulfill the needs of the target group. Biofarmaunderstanding of this aspect Biofarmacan see clearly about what must be done.

Vulnerability related to threats involves the level of seriousness of a consequence [8] also with the problem of basic human needs. For Biofarma, to understand the vulnerability, both from the aspect of the person being targeted and from the aspect of the level of importance of meeting the needs has madeBiofarmato know what activities should be a priority in the program or social activities.

Social problems are the basis for designing a program of activities including services [9]. These meant that in a Biofarma social program or activity which has done so far is to harmonize social issues in the target area of activity with Biofarma's mission and capabilities.In other words,Biofarma's CSR activities are the result of configuring social issues with the company's mission. [9] Furthermore, the results of all stages this is used as the basis for Biofarma to conduct Focus Group Discussion activities.

FGD participants are those who, based on the results of the initial study, are positioned as pinion leaders, opinion leaders or community leaders who are around Jasinga sub-district; the both topics discussed are the main problems faced by the community in the target area, and the third solution or recommendation discussed is a recommendation based on capital or strength that is or already has in the community and the target area of activity. 
Model of program arrangementof Corporate Social Responsibility PT. Biofarma (in Jasinga Bogor)

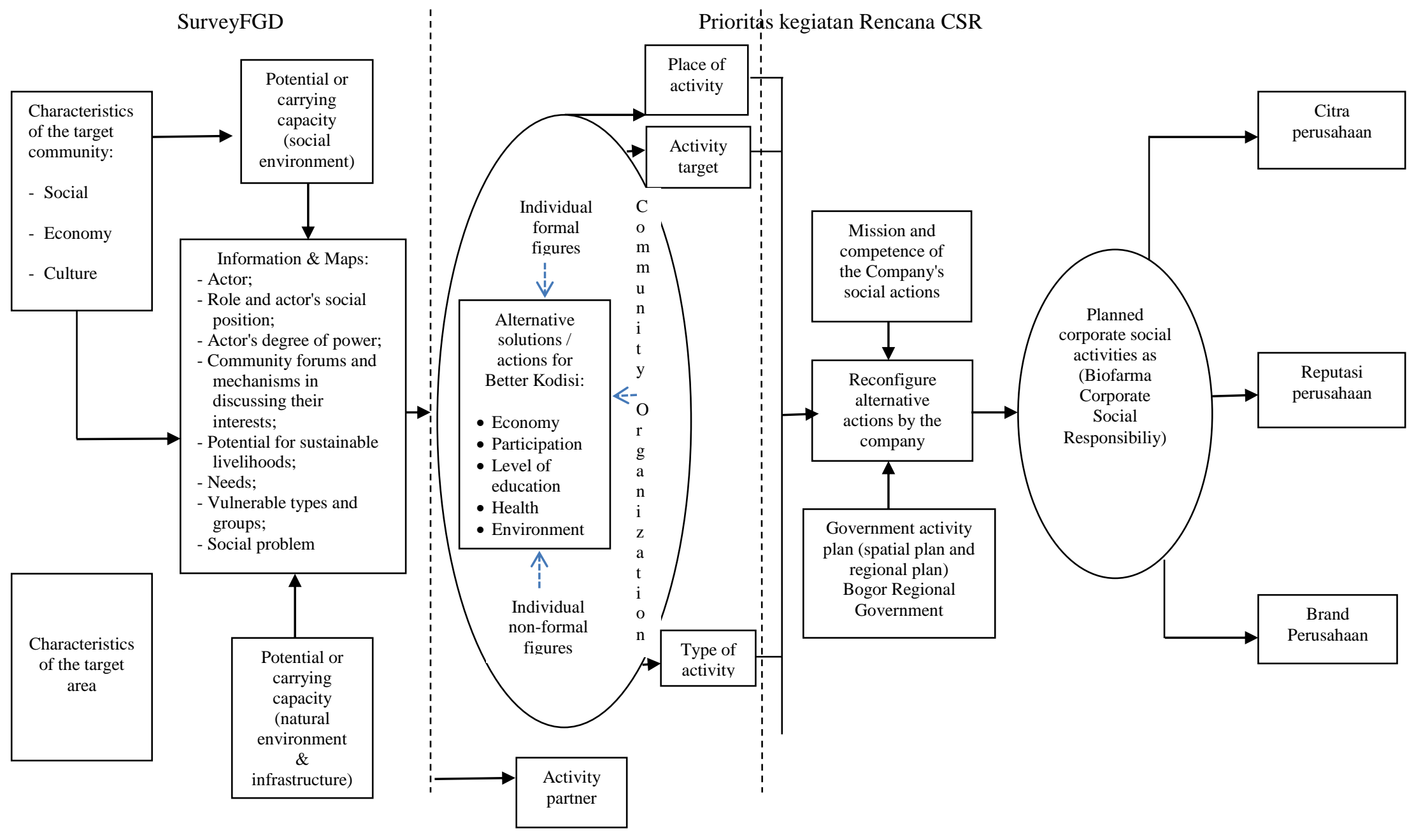





\section{Conclusions}

The survey for mapping of socio demographic, economic, cultural and environmental characteristics in the target area is the basis for PT. Biofarma (Persero) to map problems and potential or carrying capacity for corporate social activities to be carried out.Mean while, focus group discussions become a container and process of Biofarma in maturation of community characteristics, characteristics of the target area as well as social problems and activity design and mechanisms for handling social problems .

Biofarma's corporate social activities are the result of the company's reconfiguration of the thoughts obtained from the community after being aligned with the plans for developing spatial use and local government activities and the company's goals, interests and objectives.

The model of corporate social activities arrangement as a Corporate Social Responsibility (CSR) like this, is believed by Biofarma as a model that has a level of accuracy to meet the needs and solutions in solving social problems in the corporate environment, even though this development model only produces accuracy in the micro level of the social environment company.

\section{References}

[1] J. Ann, S. Dean, dan S. White, "Mapping the Development of Conditions for Collaborative Learning in School Communities of Practice," 2015.

[2] R. Bolden, "Distributed Leadership in Organizations : A Review of Theory and Research," vol. 13, hal. 251-269, 2011.

[3] M. T. Imperial, S. Ospina, E. Johnston, R. O. Leary, J. Thomsen, dan P. Williams, "Understanding leadership in a world of shared problems : advancing network governance in large landscape conservation," no. March 2019, 2016.

[4] P. Balkundi dan M. Kilduff, The ties that lead: A social network approach to leadership, vol. 17. 2006.

[5] FAO, "Methodological Guide for Designing and Implementing a Multimedia Communication Strategy Methodological Guide for Designing and Implementing," in COMMUNICATION FOR DEVELOPMENT MANUAL, no. April, 2002.

[6] D. Stein dan C. Valters, "UNDERSTANDING THEORY OF CHANGE IN INTERNATIONAL DEVELOPMENT," Justice Secur. Res. Program., vol. 1, no. August, 2012.

[7] P. Cooke, "REGIONAL INNOVATION SYSTEMS: AN EVOLUTIONARY APPROACH." 1996.

[8] J. Morris, "Theories and models ofbehaviour and behaviour change," in 1, 2012, hal. 1-27.

[9] D. B. Kristen Pue, Christian Vandergeest, "Toward a Theory of Social Innovation," Semant. Sch., no. 1, 2016. 